\title{
Investigation of Biophysical Migration Parameters for Normal Tissue and Metastatic Cancer Cells After Radiotherapy Treatment
}

\author{
Valeria Panzetta ${ }^{1,2 \star}$, Giuseppe La Verde ${ }^{3,4}$, Mariagabriella Pugliese ${ }^{3,5}$, Cecilia Arrichiello ${ }^{6}$, \\ Paolo Muto ${ }^{6}$, Marco La Commara ${ }^{3,4}$, Vittoria D'Avino ${ }^{3}$, Paolo A. Netti ${ }^{1,2}$ and \\ Sabato Fusco ${ }^{1,2 *}$ \\ ${ }^{1}$ Centro di Ricerca Interdipartimentale sui Biomateriali, Università degli Studi di Napoli Federico II, Naples, Italy, ${ }^{2}$ Center for \\ Advanced Biomaterial for Health Care, Istituto Italiano di Tecnologia, Naples, Italy, ${ }^{3}$ Istituto Nazionale di Fisica Nucleare \\ (INFN), Sezione di Naples, Naples, Italy, ${ }^{4}$ Dipartimento di Farmacia, Università degli Studi di Napoli Federico II, Naples, Italy, \\ ${ }^{5}$ Dipartimento di Fisica "Ettore Pancini", Università degli Studi di Napoli Federico II, Naples, Italy, ${ }^{6}$ Radiotherapy Unit, Istituto \\ Nazionale Tumori-Istituti di Ricovero e Cura a Carattere Scientifico (IRCCS)-Fondazione "G. Pascale", Naples, Italy
}

OPEN ACCESS

Edited by:

Vincenzo Patera,

Sapienza University of Rome, Italy

Reviewed by:

Andrea Attili,

National Institute of Nuclear Physics of

Rome, Italy

Alexander Helm,

GSI Helmholtz Centre for Heavy lon

Research, Germany

*Correspondence:

Valeria Panzetta

valeria.panzetta@unina.it

Sabato Fusco

sabfusco@unina.it

Specialty section:

This article was submitted to

Medical Physics and Imaging,

a section of the journal

Frontiers in Physics

Received: 24 June 2020

Accepted: 24 August 2020

Published: 06 October 2020

Citation:

Panzetta V, La Verde G, Pugliese M, Arrichiello C, Muto P, La Commara M,

$D$ 'Avino V, Netti PA and Fusco $S$

(2020) Investigation of Biophysical

Migration Parameters for Normal

Tissue and Metastatic Cancer Cells

After Radiotherapy Treatment.

Front. Phys. 8:575906.

doi: 10.3389/fphy.2020.575906
A large body of literature has demonstrated that the mechanical properties of microenvironment have a key role in regulating cancer cell adhesion, motility, and invasion. In this work, we have introduced two additional parameters, named cell trajectory extension and area traveled by cell, to describe the tendency of normal tissue and metastatic cancer cells to move in a directional way when they interact with physio-pathological substrates, characterized by stiffnesses of 1-13 kPa, before and after treatment with 2 doses of X-rays (2 and $10 \mathrm{~Gy}$ ). We interpreted these data by evaluating also the impact of substrate stiffness on 2 morphological parameters which indicate not only the state of cell adhesion, but also cell polarization, prerequisite to directional movement, and the formation of protrusions over cell perimeters. We believe that a so wide analysis can give an efficient and easily readable overview of effects of radiation therapy on cell-ECM crosstalk when used as therapeutic agent.

Keywords: breast cancer, mechanobiology, cell motility analysis, extracellular matrix stiffness, radiotherapy

\section{INTRODUCTION}

Cells have continuous interactions with surrounding environments and the relative mechanical dynamics are today recognized as powerful conditioning factors for cells' behavior [1-5]. The healthy functioning of many human tissues, indeed, originates from the correct interactions between cell cytoskeleton and extracellular matrix (ECM). When altered by genetic or environmental factors, they have a determinant contribution in many diseases' occurrence and progression [6-11]. In case of tumors, where the ECM may represent up to half of the entire mass, higher level fibrillar constituents (collagen, fibronectin, etc.) and specific molecular expression profiles are found. Such modification in architecture and composition gives rise to a negative loop that induces a compromised feedback between cells and the surroundings matrix. The composition and mechanical identity of ECM, for instance, can regulate the cell epithelial-mesenchymal transition (EMT), a metastases precursor process in which cells acquire a more stem-like character. To promote migration, in fact, cancer cells have to activate differentiating genes, and degrade cell-cell junction by the downregulation of the associated proteins and the upregulation of those 
appointed to adhere and/or lyse the matrix [12-16]. It has been reported that in breast tumors the stiffness can induce the nuclear translocation of transcription factors as YAP or TWIST1, both related to the EMT process [17-20], thus suggesting a very close relationship between ECM mechanical properties and tumor metastatic potential. One of the most consolidated therapeutic strategy adopted this day to contrast tumor progression is the radiotherapy (RT). Although its direct and well-established cytotoxic effect on cancer cells by DNA damage, different reports in literature suggested that in some cases hypoxia, typical of different tumors, can reduce the efficacy of RT, influencing the outcome of treatment of tumor, and leading to high recurrence and increased distant metastases [21]. On the other hand, there is a large evidence that the dose heterogeneity across normal tissue (dose gradient) and the modification of normal tissue tolerance to dose when irradiated volume changes (volume effects) have an important impact on the problem concerning second cancer risks $[22,23]$. The dose-volume question is principally related to conventional and $3 \mathrm{D}$ conformal radiation therapy, whereas modern techniques and, in particular, intensity modulated radiation therapy (IMRT) seems to reduce the risks of second cancer risks [24]. Several mechanisms that promote this counterproductive effect have been identified, including vascular damage, EMT, and cytokine production [25]. The clinical significance of these findings is still largely unknown and new cell biophysical parameters have to be identified in order to assess how RT treatments can promote increased cell migration $[26,27]$ and enhanced growth of distant metastases $[25,28]$ as well as reduction of cell migration $[29,30]$ and inhibition of distant tumor growth, also known as the abscopal effect [31]. Along this path, we proposed here a continuation of our previous work [29] by the introduction of new biophysical parameters that can be used by different researcher interested into basic and clinical translation of mechanobiology investigation. In particular, in this study we focused our attention on breast cancer, a consolidated model used to understand cancer progression and metastasis and generally treated with RT from stages I to III to reduce the risk of recurrence after surgery. In details, we have investigated the behavior of a normal epithelial cell line (MCF10A) and a highly aggressive and invasive adenocarcinoma cell line (MDA-MB-231) through a migration experimental campaign on polyacrylamide (PAAm) substrates mimicking pathophysiological stiffness $(1-13 \mathrm{kPa})$. Study was conducted in control conditions and $72 \mathrm{~h}$ after the exposure to two different doses of X-rays, 2 and $10 \mathrm{~Gy}$, which represent the daily dose in radiotherapy treatment and the single maximum dose for the treatment of metastasis. In order to obtain a more detailed comparison of the cells' responses to RT to ECM stiffness simulating pathophysiological microenvironments, two biophysical parameters and the mean square displacement (MSD) of the cells were derived from the analysis of the trajectory. The single and combined evaluation of these parameters, together with the analysis of cell morphological features, gives more insights into the effects of RT on cell-ECM crosstalk when used as therapeutic agent.

\section{MATERIALS AND METHODS}

\section{Substrate Preparation and Functionalization}

PAAm substrates with two different mechanical properties were produced by using two solutions of acrylamide and methylene-bis-acrylamide ( $4 \%$ acrylamide $/ 0.15 \%$ methylene-bisacrylamide and $10 \%$ acrylamide $/ 0.1 \%$ methylene-bis-acrylamide corresponding to 1.3 and $13 \mathrm{kPa}$, respectively) and then functionalized with bovine collagen type I. More detailed information can be found in [32].

\section{Cell Culture and Irradiation}

MCF10A cells were grown in Lonza mammary epithelium-based medium (MEBM), supplemented with bovine pituitary extract (BPE), human epidermal growth factor (hEGF) (0.1\%), insulin $(0.1 \%)$, hydrocortisone $(0.1 \%)$, gentamicin-amphotericin (GA$1000 ; 0.1 \%)$.

MDA-MB-231 cells were grown in Lonza Dulbecco's modified Eagle medium (DMEM/F-12) supplemented with 10\% fetal bovine serum (FBS, Gibco, Eggenstein, Germany), 1\% Lglutamine (Sigma, St. Louis, MO, USA), and $1 \%$ penicillinstreptomycin (Sigma, St. Louis, MO, USA).

$24 \mathrm{~h}$ after cell culture, MCF10A and MDA-MB-231 cells were exposed to two different doses of X-rays, 2 and $10 \mathrm{~Gy}$, with a dose rate equal to $5 \mathrm{~Gy} / \mathrm{min}$, using a $6 \mathrm{MeV}$ energy beam, at the National Cancer Institute "PASCALE" of Naples. Additional information can be found in [29].

\section{Migration Parameters}

MCF10A and MDA-MB-231 cells were cultured on PAAm substrates at a final density of 1,000 cells $/ \mathrm{cm}^{2}$, to guarantee a sparse-cell condition also $72 \mathrm{~h}$ after irradiation (time of analysis), necessary to avoid the formation of cell-cell contacts that could override the effect of substrate stiffness. Cell migration experiment were performed as previously reported [29]. Briefly, images of cells were acquired every $10 \mathrm{~min}$ for a total duration of $24 \mathrm{~h}$. Single cell trajectories were determined using ImageJ and Manual Tracking plugin (http://rsweb.nih.gov/ij/). Their orientation was calculated by using the ellipse-fitting function in Image $J$ and, then, cell trajectories were rigidly rotated around the starting point $\mathrm{P}(\mathrm{x}(0), \mathrm{y}(0))$ by using the rotation matrix as represented in Figure 1. After the coordinate transformation, we obtained the new coordinates $\mathrm{x}^{\prime}(\mathrm{t})$ and $\mathrm{y}^{\prime}(\mathrm{t})$ at every time $\mathrm{t}$ and the principal direction of the rotated trajectory results to be aligned to $y^{\prime}$-axis. Once rotated, the net displacements traveled along $\mathrm{x}^{\prime}$ - and $\mathrm{y}^{\prime}$-directions were calculated as follows

$$
\begin{aligned}
& \Delta x^{\prime}=x_{\text {max }}^{\prime}-x_{\text {min }}^{\prime} \\
& \Delta y^{\prime}=y_{\text {max }}^{\prime}-y_{\text {min }}^{\prime}
\end{aligned}
$$

where $\mathrm{x}^{\prime} / \mathrm{y}_{\max }^{\prime}$ and $\mathrm{x}^{\prime} / \mathrm{y}_{\min }^{\prime}$ are the maximum ad the minimum values of the rotated coordinates $\mathrm{x}^{\prime}$ and $\mathrm{y}^{\prime}$. 

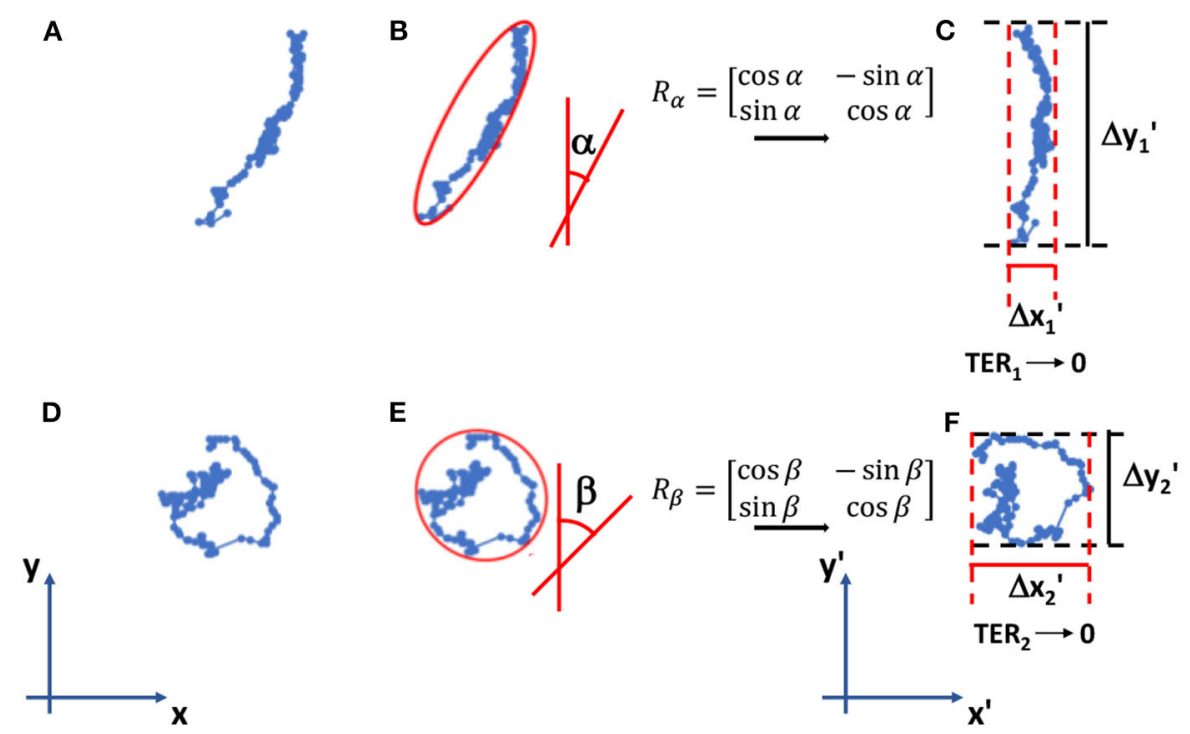

FIGURE 1 | Examples of cell trajectories (A-D) in the reference system. Their orientations $\alpha$ and $\beta$ are calculated using the fitting-ellipse function in Image $\mathrm{J}$ (B-E) and then the rotation matrices $R_{\alpha}$ and $R_{\beta}$ rotate the trajectories in the new reference system $x^{\prime}-y^{\prime}$ (C-F). Here, we calculate TER parameter as indicated in formulas (1)-(3). $\mathrm{TER}_{1}$ approaches to 0 (elongated trajectory), whereas TER $\mathrm{R}_{2}$ is close to 1 (round/random trajectory).

The trajectory extension ratio (TER) and the area traveled (AT) were calculated with the following expressions

$$
\begin{aligned}
\text { TER } & =\frac{\Delta x^{\prime}}{\Delta y^{\prime}} \\
A T & =\frac{\pi \Delta x^{\prime} \Delta y^{\prime}}{4}
\end{aligned}
$$

MSD on $\mathrm{x}^{\prime}$ - and $\mathrm{y}^{\prime}$ - directions $\left(\mathrm{MSD}_{\mathrm{x}}\right.$ and $\left.\mathrm{MSD}_{\mathrm{y}}\right)$ were calculated, starting from rotated trajectories, using the following formula:

$$
\begin{aligned}
& \operatorname{MSD}_{x}(\tau)=\left\langle\left[x^{\prime}(t-\tau)-x^{\prime}(t)\right]^{2}\right\rangle \\
& \operatorname{MSD}_{y}(\tau)=\left\langle\left[y^{\prime}(t-\tau)-y^{\prime}(t)\right]^{2}\right\rangle
\end{aligned}
$$

where $\mathrm{x}^{\prime}(\mathrm{t})$ and $\mathrm{y}^{\prime}(\mathrm{t})$ are the rotated coordinates of cell at time $\mathrm{t}$, $\tau$ is the lag time and $<>$ indicated the temporal mean.

\section{Cell Morphological Parameters}

MCF10A and MDA-MB-231 cells were cultured on PAAm substrates at a final density of $1,000 \mathrm{cells} / \mathrm{cm}^{2}$. Cells were fixed and stained for the evaluation of morphological parameters in control condition and $72 \mathrm{~h}$ after irradiation. Actin cytoskeleton and nuclei were stained with Alexa 488 phalloidin and Hoechst 33342, respectively. More detailed information on staining protocol can be found in [29]. Images of stained cells were acquired with Olympus IX81 inverted microscope equipped with a $10 \times$ objective. Images were imported into ImageJ software (NIH, Bethesda, MD, USA) for quantification of cell morphological parameters. We used nuclei to locate isolated cells. Individual cells, identified by visualization of single nuclei, were outlined and changes in cell shape in control and irradiated conditions were quantified by two morphological parameters, the shape factor (SF) and circularity index (CI), defined as follows:

$$
\begin{aligned}
& S F=\frac{4 \pi A}{P^{2}} \\
& C I=\frac{\text { axis } s_{\text {minor }}}{\text { axis }}
\end{aligned}
$$

where $\mathrm{A}$ and $\mathrm{P}$ are the area and the perimeter of cells calculated by using the "Measure" command in ImageJ, whereas axis major and axis minor are the major and the minor axis of the best-fitting ellipse determined by using the ellipse-fitting function in ImageJ.

\section{Statistical Analysis}

Statistical comparisons were performed with a Student's unpaired test. $P$-values of $<0.05$ denote statistically significant differences.

\section{RESULTS}

\section{Migration Parameters}

Time-lapse video analysis was performed to compare the motility of mammary epithelial and adenocarcinoma cells on polyacrylamide substrates with different stiffness's, 1.3 and 13 $\mathrm{kPa}$, in response to irradiation with 2 doses of X-rays (2 and $10 \mathrm{~Gy})$. In order to describe the ability of cells to move and their tendency to do it in a directional way, we introduced two additional parameters defined in Materials and Methods section: TER and AT by the cells. In particular, to individuate the principal direction of displacement, the trajectories were rotated by the orientation angle calculated using the fitting-ellipse function in ImageJ (Figures 1B-E) and, then, TER was calculated as indicated in formula 3. Analyzing the definition, TER can vary 


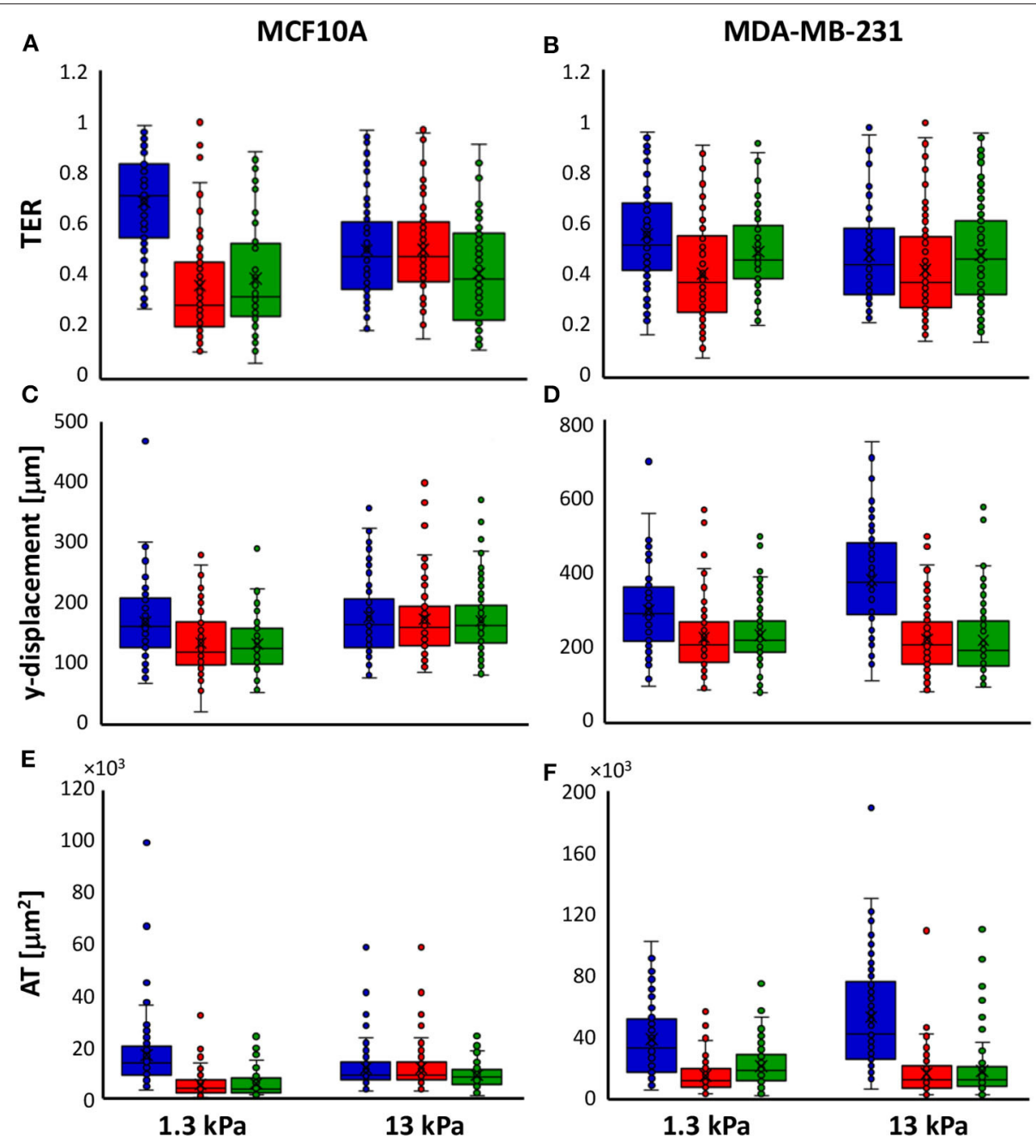

FIGURE 2 | Box plots (mean, median, interquartile range, and outliers) of TER (A,B), y-displacement (C,D) and AT (E,F) parameters of MCF10A (A-E) and MDA-MB-231 cells (B-F) in control condition (blue) and $72 \mathrm{~h}$ after irradiation with doses of 2 Gy (red) and 10 Gy (green). $n>58$ for MCF10A cells, $n>82$ for MDA-MB-231 cells.

between 0 and 1 and is inversely related to the directionality of cells: values close to 1 indicate random trajectories, whereas when TER approaches to 0 the trajectories are approximated with a straight line (Figure 1). It is also important to highlight that in our analysis, we did not consider the values of orientation angles, because our substrates are homogeneous and no chemical or topographic pattern is present on them; consequently, the orientation angles are homogeneously distributed (data not shown). TER of both normal and cancer cell lines was strongly affected by substrate stiffness. In particular, TER of MCF10A cells decreased of 27\% (Figure 2A), whereas that of MDA-MB231 cells of $14 \%$ when substrate stiffness increased, indicating that the directionality of cell trajectories was greater on stiffer substrates mimicking pathological environment (Figure 2B). By a deep analysis of these data, it is possible to observe that, even though the stiffness affected the directionality of both cell lines, this effect was more relevant for normal cells than for tumor ones: on soft substrate, TER of MDA-MB-231 cells is 19 and 5\% lower than that of MCF10A cells, respectively, on soft and stiff substrates, but the difference is significant only on $1.3 \mathrm{kPa}$ polyacrylamide ( $t$-test, $P=1.5 \times 10^{-5}$, Figures $2 \mathrm{~A}, \mathbf{B}$ ). Results demonstrated that the stiffness of the microenvironment by itself could enhance cell directionality, but at the same time the tumor metastatic phenotype confers on cells properties that are critical for invasion. Besides TER, we analyzed also two other parameters, the displacement along the principal direction $\mathrm{y}^{\prime}$ and AT. MCF10A cells moved along $\mathrm{y}^{\prime}$ in a not dependent way from substrate stiffness (Figure 2C, Table 1), whereas their AT decreased of $28 \%$ in a significant way (Figure 2E, Table 1) when they adhere on stiff substrate. On the contrary, both displacement along $y^{\prime}$ and AT of MDA-MB-231 exhibited a significant increase of 27 and $38 \%$ when cells are cultured on stiff substrate rather than on soft one (Figures 2D-F, Table 1). After the evaluation of cell response to substrate stiffness in control 
TABLE 1 | Statistical analysis for trajectories data.

\begin{tabular}{|c|c|c|c|c|c|c|}
\hline & & \multirow{2}{*}{$\frac{\text { Control }}{13 \mathrm{kPa}}$} & \multicolumn{2}{|c|}{2 Gy } & \multicolumn{2}{|c|}{$10 \mathrm{~Gy}$} \\
\hline & & & $1.3 \mathrm{kPa}$ & $13 \mathrm{kPa}$ & $1.3 \mathrm{kPa}$ & $13 \mathrm{kPa}$ \\
\hline \multirow[t]{6}{*}{ Control } & $1.3 \mathrm{kPa}$ & 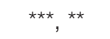 & 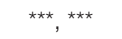 &  & $* \star * * *$ & 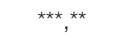 \\
\hline & & NS, \#\#\# & \#\#\#, \#\#\# & NS, \#\#\# & \#\#\#, \#\#\# & NS,\#\#\# \\
\hline & & ๆๆ, ๆๆ & ๆাগ, ๆগা & ๆๆ, ११ & ๆাগ, ๆๆগ & ๆাগী,ๆাा \\
\hline & $13 \mathrm{kPa}$ & & ${ }^{* \star *},{ }^{*}$ & $N S,{ }^{*}$ & ${ }^{* \star}, \mathrm{NS}$ & ${ }^{* *}, \mathrm{NS}$ \\
\hline & & & \#\#\#, \#\#\# & NS, \#\#\# & \#\#\#, \#\#\# & NS, \#\#\# \\
\hline & & & ๆগা, ๆগা & NS, ๆাा & গাগ,, ๆাগ & ๆๆ, ๆๆ \\
\hline \multirow[t]{6}{*}{2 Gy } & $1.3 \mathrm{kPa}$ & & & ${ }^{\star \star \star}$, NS & $N S,{ }^{* * *}$ & NS, * \\
\hline & & & & \#\#\#, NS & NS, NS & \#\#\#, NS \\
\hline & & & & ๆๆ,ๆๆๆ & NS, NS & ๆাগ, ๆাগ \\
\hline & $13 \mathrm{kPa}$ & & & & 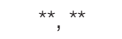 & $\star \star *, *$ \\
\hline & & & & & \#\#\#, NS & NS, NS \\
\hline & & & & & ๆাগ, ๆશা & ๆๆๆी, ๆๆ \\
\hline \multirow[t]{3}{*}{10 Gy } & $1.3 \mathrm{kPa}$ & & & & & NS, NS \\
\hline & & & & & & $\# \# \#$, NS \\
\hline & & & & & & ๆๆๆ, ๆাा \\
\hline
\end{tabular}

Asterisks (*) refer to TER of MCF10A (left) and MDA-MB-231 cells (right), hash signs (\#) to

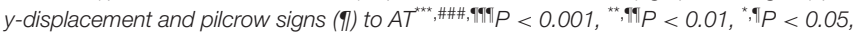
NS, not significant.

condition, we investigated the effects of two different doses of $\mathrm{X}$-rays, 2 and $10 \mathrm{~Gy}$, on the migration parameters. Seventy-two hours after irradiation, MCF10A cells cultured on soft substrate responded to irradiation by reducing all the parameters in a very significant way in an independent manner from the delivered dose: TER decreased of $47 \%$, the principal displacement of $21 \%$ and $\mathrm{AT}$ of $68 \%$ when cells were irradiated with the lower dose of $2 \mathrm{~Gy}$; whereas TER, the principal displacement and AT decreased of $43 \%, 22$ and $66 \%$ in the case of the dose of $10 \mathrm{~Gy}$ (Figures 2A-E, Table 1). On stiff substrate, the dose of $2 \mathrm{~Gy}$ had no effects, whereas cells responded to the higher dose of X-rays by reducing their migration parameters also in this case, even though in a less pronounced way compared to cells adhering on $1.3 \mathrm{kPa}$ polyacrylamide (TER, the principal displacement and AT reduced of 15, 10, and 30\%, respectively) (Figures 2A-E, Table 1). Metastatic cancer cells resulted to be more sensitive to irradiation, in particular on stiff substrate. Only TER was more significantly reduced when cells adhered on soft substrate: it decreased of 27 and $12 \%$ after irradiation with doses of 2 and $10 \mathrm{~Gy}$, respectively, reaching values close or lower than that of control cells on stiff substrate (Figure 2B, Table 1). However, the reduction of TER, that is associated to a greater directionality during migration, was also accompanied by a significant decrease of the principal displacement (26 and $20 \%$ after irradiation with 2 and 10 Gy, respectively) and AT (61 and $45 \%$ after irradiation with 2 and $10 \mathrm{~Gy}$, respectively) (Figures 2D-F, Table 1). On stiff substrate, TER reduced only when cells were irradiation with the lower dose (reduction of $12 \%$ ), whereas the principal displacement diminished by 42 and $46 \%$ and AT by 69 and $66 \%$ after irradiation with 2 and $10 \mathrm{~Gy}$, respectively (Figures 2B-F, Table 1).

In order to interpret our data in relation with previous results concerning cell velocity and reported in [29], we performed also a correlation analysis between TER and velocity data. In the case of normal tissue cells, TER and velocity resulted to be not or negatively correlated in control condition (correlations are equal to -0.11 and close to 0 on soft and stiff substrates, respectively), whereas we observed a weak positive correlation for cells irradiated with the dose of $2 \mathrm{~Gy}$ ( 0.11 on soft substrate and 0.15 on the stiff one) and a moderate positive correlation after irradiation with the dose of $10 \mathrm{~Gy}(0.26$ on soft substrate and 0.24 on the stiff one). TER and velocity of metastatic cancer cells exhibited low or absent correlation on soft substrate (0.09 in control condition and $\sim 0$ after irradiation with both doses), indicating that their directional behavior is weakly affected by the velocity (as also indicated by the high values of persistence time evaluated in [29] in all conditions and also when their velocities are reduced in a drastic way. When metastatic cells were cultured on stiff substrates, the correlation increases passing by 0.05 in control condition to 0.19 and 0.17 after irradiation with 2 and $10 \mathrm{~Gy}$, exhibiting a behavior similar to that of normal tissue cells.

\section{Mean Square Displacements}

In our analysis, we decomposed the MSD in the two components calculated along directions $\mathrm{x}$ and $\mathrm{y}$ after rotation, $\mathrm{MSD}_{\mathrm{x}}$ and $\mathrm{MSD}_{\mathrm{y}}$, and reported them in a $\log -\log \operatorname{plot}\left(\log \left(\mathrm{MSD}_{\mathrm{x} / \mathrm{y}}\right)\right.$ on the $\mathrm{y}$-axis and $\log ($ Lag Time) on the $\mathrm{x}$-axis (Figure 3$)$. The slope $\alpha$ of these plots is a suitable indicator for cell directionality: log-log curve with slope $\alpha=1$ indicates a random migration, whereas we describe as subdiffusive cell motion characterized from $\alpha<1$ and superdiffusive a MSD with $1<\alpha<2(\alpha=2$ for cells that move along a straight line); $\log \left(\mathrm{MSD}_{\mathrm{x} / \mathrm{y}}\right)$ curve showing a slope close to zero indicates a random caged migration.

In control condition, MCF10A cells on soft substrate exhibited MSD with similar amplitude along the two directions (the $\mathrm{MSD}_{\mathrm{x}} / \mathrm{MSD}_{\mathrm{y}}$ ratio was comprised between 0.8 and 1 at all lag times) and slopes very close to $1\left(\alpha=0.945, R^{2}=0.9804\right.$ and $\alpha=1.002, R^{2}=0.986$ on 1.3 and $13 \mathrm{kPa}$, respectively), indicating that there was not a preferential direction during migration, in agreement with TER data (Figure 3). When cells were cultured in control condition on stiff substrate, the log$\log$ plot of $\mathrm{x}$-component of MSD was not well-fitted with a linear equation $\left(\alpha=0.4529, R^{2}=0.6576\right)$, because cell migration showed two different regimes: in the first $4 \mathrm{~h} \log \left(\mathrm{MSD}_{\mathrm{x}}\right)$ exhibited a slope close to $1\left(\alpha=0.9902, R^{2}=0.9737\right)$, whereas in the rest of investigated time the curve flattened and the slope approached zero, indicating a caged migration (Figure 3). On the contrary, the log-log plot of y-component of MSD exhibited a slope close to $1.2\left(\alpha=1.1752, R^{2}=0.9737\right)$ and its amplitude increased up to $1,400 \%$ compared to $\mathrm{MSD}_{\mathrm{x}}$, meaning that cells move preferentially along $\mathrm{y}$-axis as also indicated by TER parameter (Figure 2). Metastatic cells denoted a behavior, in terms of MSD, more similar to normal tissue cells on stiff substrate. In fact, independently of substrate stiffness, their $\mathrm{MSD}_{\mathrm{x}}$ showed a subdiffusive behavior with slopes equal to 0.7314 $\left(R^{2}=0.8562\right)$ and $0.794\left(R^{2}=0.8645\right)$ on 1.3 and $13 \mathrm{kPa}$ substrates, respectively. However, also in these cases it is possible to observe two different regimes: in the first $4 \mathrm{~h}$ both $\log$-log plots slopes were close to $1.2\left(\alpha=1.2282, R^{2}=0.9992\right.$ and $\alpha$ $=1.1578, R^{2}=0.9975$ on 1.3 and $13 \mathrm{kPa}$, respectively), whereas 


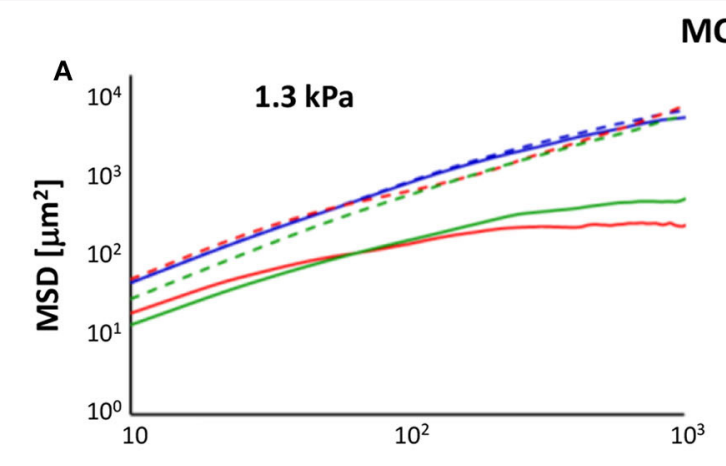

\section{MCF10A}

B

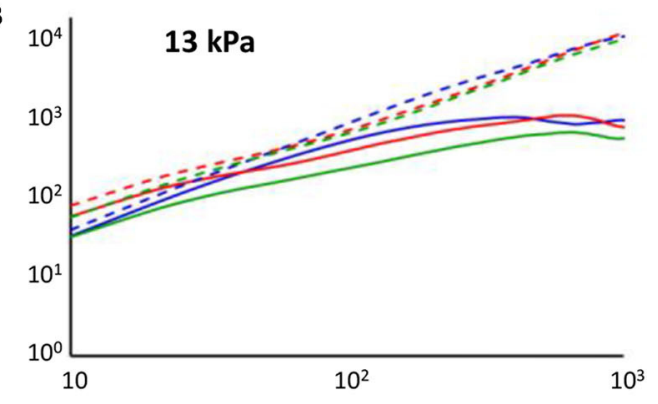

MDA-MB-231
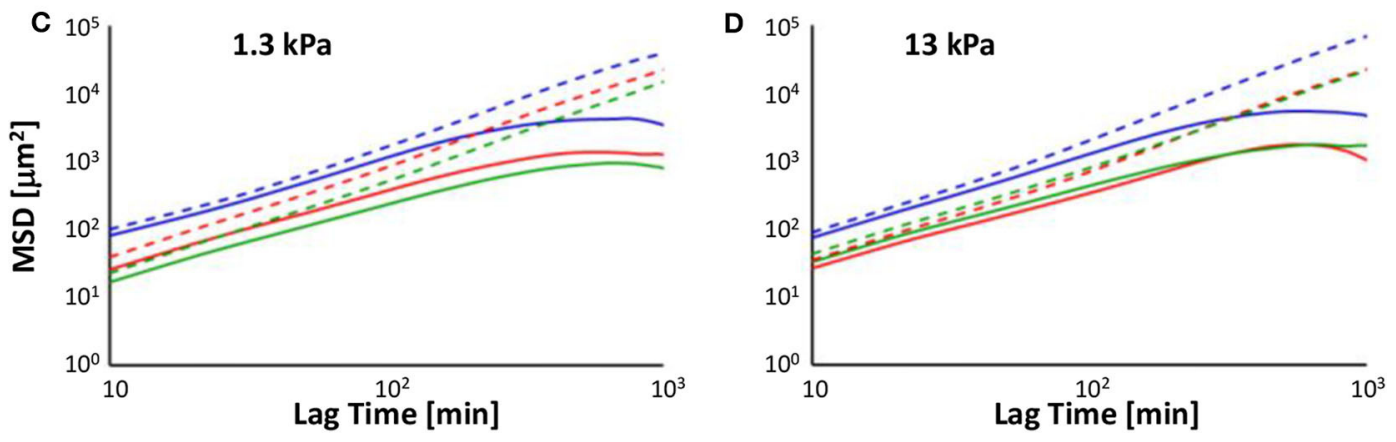

FIGURE 3 | Log-log plot of MSDs along x'- (solid line) and y'- (dotted lines) directions of MCF10A (A,B) and MDA-MB-231 cells' (C,D) trajectories on soft (A-C) and stiff (B-D) PAAm substrates, in control condition (blue) and $72 \mathrm{~h}$ after irradiation with doses of $2 \mathrm{~Gy}$ (red) and 10 Gy (green).

they approached to zero successively, indicating again a caged migration (Figure 3). The log-log plot of y-component of MSD exhibited slopes higher than $1\left(\alpha=1.3864, R^{2}=0.998\right.$ and $\alpha=1.526, R^{2}=0.990$ on 1.3 and $13 \mathrm{kPa}$, respectively) and their amplitudes increased up to 1,400 and $2,100 \%$ compared to $\mathrm{MSD}_{\mathrm{x}}$ on 1.3 and $13 \mathrm{kPa}$ substrates. These findings support the results obtained in terms of TER: MDA-MB-231 cells were characterized by a more directional movement compared to MCF10A and this characteristic was particularly relevant on stiff substrate (Figure 3D), as also indicated by higher persistence time evaluated in our previous work [29]. Seventy-two hours after irradiation, the significant reduction of TER of normal tissue cells was accompanied by a change of mode of migration, as evidenced by the analysis of MSD. On soft substrate, the slope of MSDx was sensitively lower than 1 for both doses $(\alpha=0.3737$, $R^{2}=0.7826$ and $\alpha=0.6392, R^{2}=0.9155$ for cells irradiated with 2 and $10 \mathrm{~Gy}$, respectively), but as in control condition on stiff substrate, it is possible to individuate two different regimes: cells irradiated with lower dose exhibited $\log \left(\mathrm{MSD}_{\mathrm{x}}\right)$ with a slope equal to $0.7039\left(R^{2}=0.9726\right)$ until $4 \mathrm{~h}$, whereas this value decreased to 0 successively (caged migration); cells irradiated with 10 Gy showed a pure diffusive motion until $4 \mathrm{~h}(\alpha=0.9479$, $\left.R^{2}=0.9926\right)$ and then a subdiffusive migration $\left(\alpha=0.2799, R^{2}=\right.$ $0.9143)$. On the other side, $\log \left(\mathrm{MSD}_{\mathrm{y}}\right)$ exhibited a slope slightly higher than 1 ( $\alpha=1.0501, R^{2}=0.9883$ and $\alpha=1.069, R^{2}=0.994$ for cells irradiated with 2 and $10 \mathrm{~Gy}$, respectively) and $\mathrm{MSD}_{\mathrm{y}}$ amplitude enhanced to values 100 and 14 higher than those of $\mathrm{MSD}_{\mathrm{x}}$ of cells irradiated with 2 and $10 \mathrm{~Gy}$. This finding indicates that irradiation had a more important effect on cells exposed to $2 \mathrm{~Gy}$, as also attested by the lower values of TER, but also that, in any case, normal tissue cells continued to preserve their less motile and directional motion on soft substrate (Figures 2, 3). MCF10A cells cultured on stiff substrate exhibited a subdiffusive migration on $\mathrm{x}$-direction after irradiation, in fact the slopes of log-log plots resulted to be sensitively lower than 1 and equal to $0.492\left(R^{2}=0.8205\right)$ and $0.5273\left(R^{2}=0.8274\right)$ after that doses of 2 and $10 \mathrm{~Gy}$ had been administered. However, also in these cases the slopes of the curves changed after the first $4 \mathrm{~h}$, passing from $\sim 0.8\left(\alpha=0.7538, R^{2}=0.9948\right.$ and $\alpha=1.069, R^{2}=0.994$ for cells irradiated with 2 and $10 \mathrm{~Gy}$, respectively) to 0 (Figure 3). On the $y$-direction the mode of migration was not importantly affected by the irradiation, in fact the slopes remained close to 1.2 , but the maximum value of $\mathrm{MSD}_{\mathrm{y}} / \mathrm{MSD}_{\mathrm{x}}$ ratio increased slightly after irradiation with the low dose and in a more relevant way when cells were treated with the high dose (the ratio passed from 14 in control condition to 18 and 24 after irradiation with 2 and $10 \mathrm{~Gy})$. The behavior of MDA-MB-231 cells was not affected in a strong way by irradiation. In particular, the slope of $\log \left(\mathrm{MSD}_{\mathrm{x}}\right)$ was lower than $1\left(\alpha=0.724, R^{2}=0.8701\right.$ and $\alpha=0.7545, R^{2}$ $=0.8946$ for cells cultured on soft substrate and irradiated with 2 and $10 \mathrm{~Gy}$, respectively, $\alpha=0.779, R^{2}=0.827$ and $\alpha=0.7579, R^{2}$ $=0.9157$ for cells cultured on stiff substrate and irradiated with 
2 and $10 \mathrm{~Gy}$, respectively), even though the dynamics motion continued to be slightly superdiffusive until $4 \mathrm{~h}(\alpha=1.1097$, $R^{2}=0.9981$ and $\alpha=1.09151, R^{2}=0.9986$ for cells cultured on soft substrate and irradiated with 2 and $10 \mathrm{~Gy}, \alpha=1.1279$, $R^{2}=0.9995$ and $\alpha=1.073, R^{2}=0.9984$ for cells cultured on soft substrate and irradiated with 2 and $10 \mathrm{~Gy}$, respectively) and entrapped at succeeding lag times. The slope of $\log (\mathrm{MSDy})$ increased slightly compared to control condition passing from 1.3864 to $1.4297\left(R^{2}=0.9991\right)$ and $1.4499\left(R^{2}=0.9996\right)$, whereas the maximum value of $\mathrm{MSD}_{\mathrm{y}} / \mathrm{MSD}_{\mathrm{x}}$ ratio increased from 14 to 26 and 32 after irradiation with 2 and $10 \mathrm{~Gy}$, when cells were attached to soft polyacrylamide. On stiff substrate, the slope of $\log (\mathrm{MSD} y)$ slightly decreased passing from 1.526 in control condition to $1.491\left(R^{2}=0.9984\right)$ and $1.4093\left(R^{2}=0.9988\right)$ and the maximum value of $\mathrm{MSD}_{\mathrm{y}} / \mathrm{MSD}_{\mathrm{x}}$ ratio increased from 21 to 28 and 23 after irradiation with 2 and $10 \mathrm{~Gy}$.

\section{Morphological Parameters}

It is extensively known that mode of cell migration is strictly correlated to cell adhesion and morphology and, for this reason, we used two additional morphological parameters, SF and CI (see Materials and Methods section), to describe the role of substrate stiffness and the effects of irradiation on these parameters. Both parameters can change between 0 and 1, where the upper bound connotes a perfect circular cell, whereas the lower bound indicates, in the case of SF, a cell with very pronounced border roughness (from a mathematical point of view we can say that the cell is characterized by a high fractal dimension), and, in the case of CI, a cell that can be approximated with a straight line. Normal cells exhibited low values of SF not dependent on substrate stiffness $(0.23$ and 0.22 on 1.3 and 13 $\mathrm{kPa}$ substrates, respectively), whereas their CI enhanced by $19 \%$ when cells are cultured on stiff substrate, indicating a more flattened and round shape (Figures $\mathbf{5 A}-\mathbf{C}$, Table 2 ). On the contrary, metastatic cancer cells exhibited a significantly lower SF on stiff polyacrylamide $(0.28$ and 0.22 on 1.3 and $13 \mathrm{kPa}$

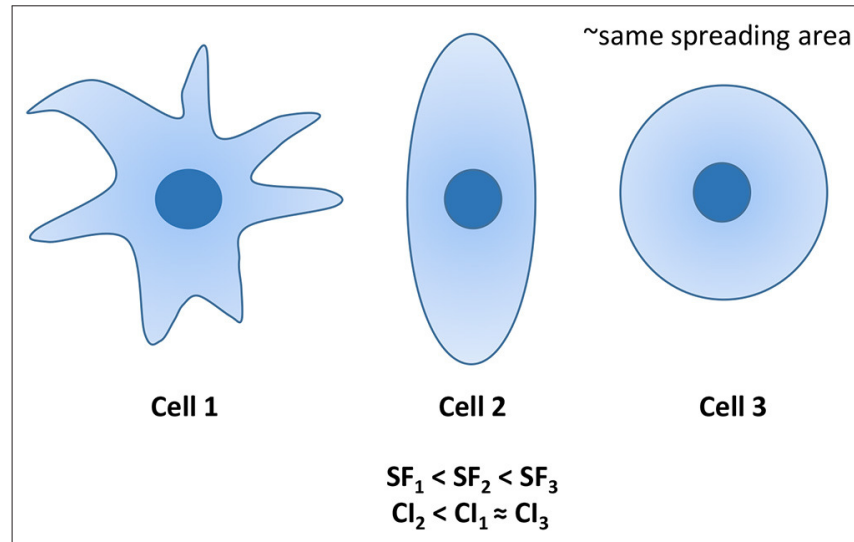

FIGURE 4 | Examples of 3 cells with similar spreading areas, but different morphologies. Cell 1 is characterized by the lowest SF, whereas its $\mathrm{Cl}$ is similar to that of the circular cell 3. Differently, cell 2 exhibits the lowest $\mathrm{Cl}$, whereas its $\mathrm{SF}$ is intermediated $\mathrm{Cl}_{1}$ and $\mathrm{Cl}_{3}$. substrates, respectively) and a CI close to that of MCF10A on soft substrate and not dependent on substrate stiffness (0.46 and 0.49 on 1.3 and $13 \mathrm{kPa}$ substrates, respectively) (Figures 5B-D, Table 2). $72 \mathrm{~h}$ after irradiation with 2 and $10 \mathrm{~Gy}$, normal cells on soft substrate reduced their SF of 18 and 14\%, whereas on stiff substrate SF increased by $16 \%$ when cells were irradiated with a dose of $2 \mathrm{~Gy}$ and decreased by $21 \%$ when the dose administered was equal to $10 \mathrm{~Gy}$ (Figure 5A, Table 2). The effects on CI were more relevant: MCF10A cells decreased their CI of 53 and $43 \%$ on soft substrate and of 42 and $36 \%$ on stiff substrate (Figure 5C, Table 2). The effects of X-rays on MDAMB-231 were not significant, except for two cases: on soft substrate SF of cells irradiated with a dose of $2 \mathrm{~Gy}$ increased by $12 \%$, whereas on stiff substrate SF of cells irradiated with a dose of $10 \mathrm{~Gy}$ increased by $36 \%$ (Figures 5B-D, Table 2). Furthermore, we analyzed in which way irradiation affected the degree to which individual morphological data deviate from the average deviation of data points from the mean by calculate the percent deviation $\mathrm{PD}\left(P D=\left[\frac{S D}{\mu}\right] \%\right.$, where $\mathrm{SD}$ is the standard of the mean and $\mu$ is the mean value of the data. In the following, we refer to $\mathrm{PD}$ of $\mathrm{SF}$ and $\mathrm{PD}$ of $\mathrm{CI}$ as $\mathrm{PD}_{\mathrm{SF}}$ and $\mathrm{PD}_{\mathrm{CI}}$. We observed that in normal tissue cells, both $\mathrm{PD}_{\mathrm{SF}}$ and $\mathrm{PD}_{\mathrm{CI}}$ increased after irradiation: on soft substrate, $\mathrm{PD}_{\mathrm{SF}}$ enhanced passing from $39 \%$ in control condition to 46 and $48 \%$ after irradiation with 2 and $10 \mathrm{~Gy}$, respectively. $\mathrm{PD}_{\mathrm{CI}}$ on soft substrate was not affected by irradiation with low dose, whereas increased from $43 \%$ in control condition to $69 \%$ when the dose of $10 \mathrm{~Gy}$ was administered. On stiff substrate, both doses significantly increased $\mathrm{PD}_{\mathrm{CI}}$, which passed from $37 \%$ in control condition to 61 and $57 \%$ after irradiation with 2 and $10 \mathrm{~Gy}$, respectively. The effects of irradiation on $\mathrm{PD}_{\mathrm{SF}}$ and $\mathrm{PD}_{\mathrm{CI}}$ of MDA-MB-231 were less important, but not absent: on soft substrate $\mathrm{PD}_{\mathrm{SF}}$ in control condition is equal to $44 \%$ and increased up to 46 and $48 \%$ after irradiation with 2 and $10 \mathrm{~Gy}$, whereas on stiff substrate it passed from 35 to $44 \%$ and $46 \%$ after the administration of the two doses if X-ray, 2 and $10 \mathrm{~Gy}$. Analyzing the $\mathrm{PD}_{\mathrm{CI}}$ of metastatic cancer cells, we observed that it changed slightly after irradiation, reducing from $43 \%$ in control condition to $41 \%$ when the cells were on soft substrate and irradiated with dose of $2 \mathrm{~Gy}$ and increasing up to $49 \%$ when the dose administered was higher $(10 \mathrm{~Gy}) . \mathrm{PD}_{\mathrm{CI}}$ related to MDA-MB-231 cells increased from 37 to $40 \%$ and $42 \%$ after irradiation with 2 and $10 \mathrm{~Gy}$, respectively.

\section{DISCUSSION}

Despite the overall breast cancer rate declined of 40\% from 1990 to 2017, breast cancer continued to be the most common cancer diagnosed and the principal cause of cancer death among women worldwide [33, 34]. Moreover, the incidence rate of metastatic disease increased until 2011 and practically all deaths from breast cancer result from the spread of breast cancer cells to other vital organs, such as lung, liver or brain, through the process of metastasis $[33,35,36]$. In order to reduce the risk of breast cancer recurrence and to alleviate the symptoms of metastasis, most of breast cancer is treated with radiation therapy [33]. Basing 


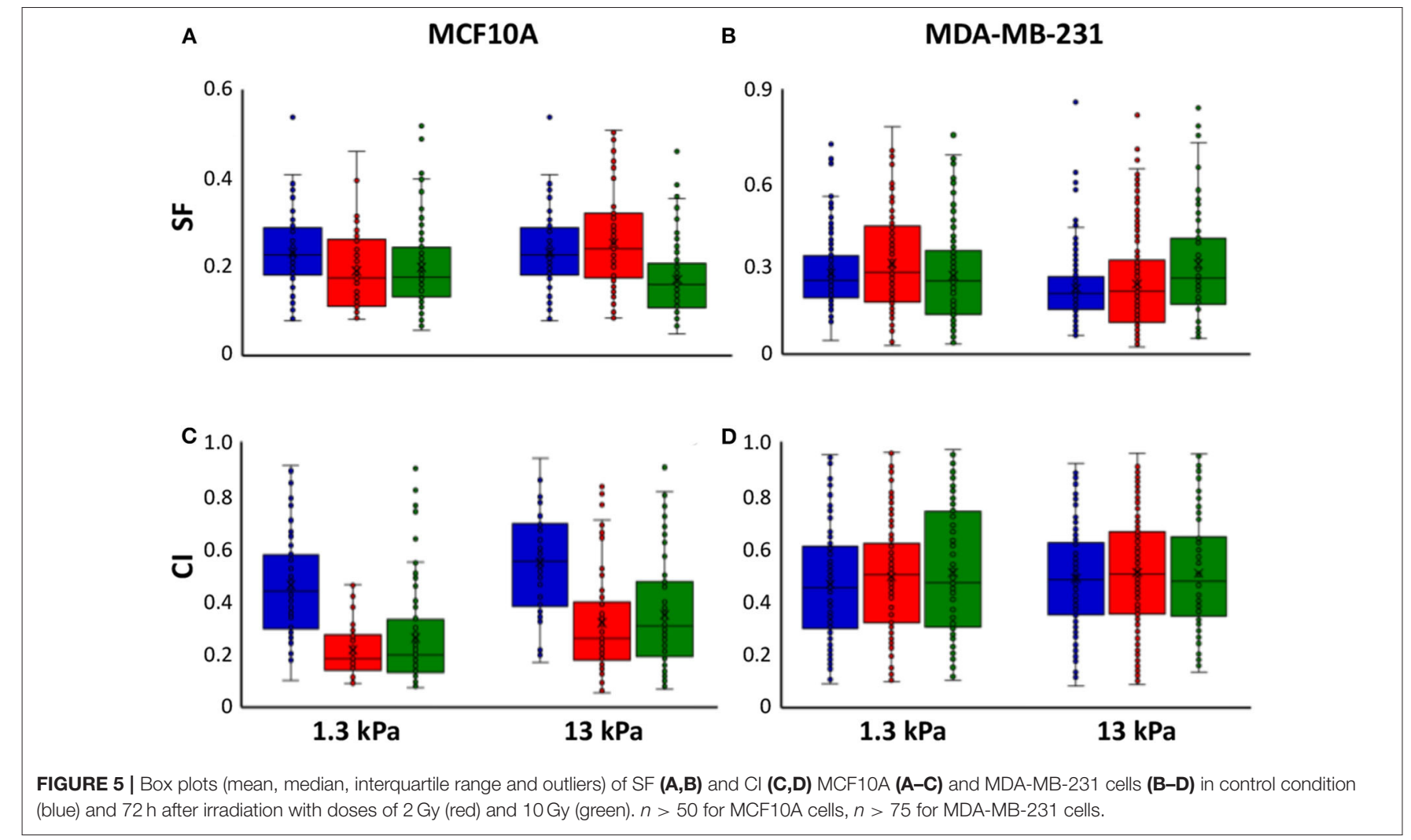

B $\quad$ MDA-MB-231

TABLE 2 | Statistical analysis for morphological data.

\begin{tabular}{|c|c|c|c|c|c|c|}
\hline & & \multirow{2}{*}{$\frac{\text { Control }}{13 \mathrm{kPa}}$} & \multicolumn{2}{|c|}{2 Gy } & \multicolumn{2}{|c|}{$10 \mathrm{~Gy}$} \\
\hline & & & $1.3 \mathrm{kPa}$ & $13 \mathrm{kPa}$ & $1.3 \mathrm{kPa}$ & $13 \mathrm{kPa}$ \\
\hline \multirow[t]{2}{*}{ Control } & $1.3 \mathrm{kPa}$ & $\begin{array}{l}\text { NS, \# } \\
\star \star \star \star \\
\text { NS }\end{array}$ & $\begin{array}{l}{ }^{*}, \# \# \# \\
{ }^{*}, \text { NS }\end{array}$ & $\begin{array}{c}\text { NS, \#\#\# } \\
{ }^{* \star}, \#\end{array}$ & $\begin{array}{c}{ }^{*}, \# \# \# \\
\text { NS, NS }\end{array}$ & $\begin{array}{l}{ }^{\star \star \star}, \# \# \\
N S, N S\end{array}$ \\
\hline & $13 \mathrm{kPa}$ & & $\begin{array}{l}\text { NS, \#\#\# } \\
{ }_{\star \star \star}, N S\end{array}$ & $\begin{array}{c}{ }^{\star}, \# \# \# \\
\text { NS, NS }\end{array}$ & $\begin{array}{c}\text { NS, \#\#\# } \\
{ }^{*}, N S\end{array}$ & $\begin{array}{l}{ }^{* \star}, \# \# \# \\
{ }^{* \star \star}, \text { NS }\end{array}$ \\
\hline \multirow[t]{2}{*}{2 Gy } & $1.3 \mathrm{kPa}$ & & & $\begin{array}{l}{ }^{\star \star \star}, \text { \#\#\# } \\
{ }_{\star \star \star \star}, N S S\end{array}$ & $\begin{array}{l}\text { NS, \# } \\
{ }^{*}, N S\end{array}$ & $\begin{array}{l}\text { NS, \#\#\# } \\
\text { NS, NS }\end{array}$ \\
\hline & $13 \mathrm{kPa}$ & & & & $\begin{array}{l}{ }^{* *}, N S \\
N S, N S\end{array}$ & $\begin{array}{l}{ }^{\star \star \star}, N S \\
N S, N S\end{array}$ \\
\hline $10 \mathrm{~Gy}$ & $1.3 \mathrm{kPa}$ & & & & & $\begin{array}{l}{ }^{*}, \# \# \\
{ }^{\star}, \text { NS }\end{array}$ \\
\hline
\end{tabular}

Asterisks (*) refer to SF of MCF10A (left) and MDA-MB-231 cells (right), hash signs (\#) to

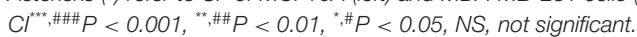

on these considerations, it becomes necessary to understand the mechanisms that underline the process of metastasis, taking into account also the contribution of the microenvironment in which cells naturally live, and to examine the effect of radiation therapy on the motile and metastatic capacity of cells.

The velocity represents the most used parameter to describe a key cellular function as the migration. Nevertheless, it could be not completely adequate to illustrate the effective proclivity of metastatic cells to move far away from the origin site toward lymph nodes and distant tissues to form secondary tumors. In our previous work [29], we used the velocity and the persistence time to indicate the effects of irradiation on the migratory behavior of mammary epithelial and adenocarcinoma cells cultured on polyacrylamide substrates of different mechanical stiffness. Here, we introduced two different parameters to further investigate the mode of cell migration: TER and AT by the cells. TER is strictly related to the directionality of the cell and it approaches to 1 when the trajectory is contained into a perfect circle (the displacements along the two orthogonal directions are exactly the same) and to 0 when the trajectory is approximated with a straight line (Figure 1). AT gives indication on the area effectively explored by the cells in a certain time of analysis ( $24 \mathrm{~h}$ here). Taken together with the velocity, these parameters can offer a more comprehensive view of the characteristics of migration of normal tissue and metastatic cancer cells on substrates mimicking different in vivo conditions (normal and tumor-like environment) and after therapeutic treatments such as radiotherapy.

The analysis of both normal tissue and metastatic cancer cell lines revealed that the extension ratio of the trajectory was strongly affected by the stiffness of the substrates. In particular, in control condition TER significantly decreased by increasing the stiffness of the substrate for both MCF10A and MDA-MB231 cells (Figures $\mathbf{2 A , B}$ ), whereas the migration velocity found in our previous work [29] decreased in normal tissue and increased in metastatic cancer cell lines as effect of ECM stiffening, respectively. On one hand, the opposite finding in terms of 
velocity in MCF10A and MDA-MB-231 cells can be explained by considering that the migration is regulated by the dynamics of focal adhesions [37, 38], that is substantially dependent on the pathophysiological state of cells. In particular, focal adhesion kinase (FAK) has a central role in the dynamic regulation of focal adhesions and cells overexpressing FAK, such as MDA-MB231 cells, displayed impaired focal adhesions and enhanced cell migration [39-42]. On the other hand, results suggest that the stiffness regulates in a similar way TER and that the stiffening of the tumor ECM increases the directionality of cell trajectory independently from cell type and, consequently, cell velocity. This result also gives more insights about previous findings on persistence time [29] and supports previous observation demonstrating that stiff substrates promote directional migration [43]. In particular, it has been demonstrated that substrate stiffness regulates RhoA/ROCK1/p-MLC and RhoA/ROCK2/pcofilin pathways, strongly implicated in the progression and metastasis of many cancers included breast cancer, through the activation of integrin $\beta 1$ and FAK [44-46]. MCF10A cells resulted to have a persistence time very close to $0 \mathrm{~min}$ independently of substrate stiffness and a TER that decrease sensitively moving from soft to stiff substrate. While an almost null persistence time could be interpreted as a random motion in terms of cell trajectory, the TER decrease clearly indicates that motion has a predominant direction, if the whole trajectory is considered along the entire time range of observation. Seventy-two hours after irradiation, MCF10A cells cultured on soft substrate decreased strongly their TER without dependence on administered dose, whereas only the dose of $10 \mathrm{~Gy}$ affected the extension rate of cells cultured on stiff substrate (Figure 2A). We think that in MCF10A cells the lengthening of the trajectories, evidenced by TER reduction (Figure $\mathbf{2 A}$, Table $\mathbf{1}$ ), was correlated to the decrease of cell velocity previously reported [29], as also evidenced by the increase of correlation between TER and velocity data. The effects of irradiation were less pronounced in MDA-MB-231 cells cultured on soft substrates (Figure 2B, Table 1), because their trajectories in control condition exhibited a more elongated and directional shape compared to normal tissue cells (Figure 2A, Table 1). However, similarly to MCF10A cells, also metastatic cells reduced the extension ratio of their trajectories, even though in a more sensitive way after the administration of the lower dose (Figures 2A,B, Table 1). On stiff substrates, only the low dose increased significantly the extension of the trajectories, but both doses, as previously observed, reduced in a drastic way the mean cell velocity (Figures 2A,B, Table 1). The reduction of the extension ratio was also in this case accompanied by a lowered cell velocity and, for this reason, an analysis of both displacements along the principal direction of the migration and area traveled by the cells was performed. MCF10A cells showed a displacement in the principal direction not affected by ECM stiffness, whereas the area traveled in $24 \mathrm{~h}$ was significantly lower on stiff substrate, as consequence of the reduced velocity but a more directional movement which reduced the extension ratio (Figures $2 \mathrm{~A}-\mathbf{E}$, Table 1). On the contrary, metastatic cells exhibited displacement in the principal direction and migration area increasing with substrate stiffness (Figures 2D-F, Table 1), in agreement with the mean velocity and the extension of trajectories. These findings indicate that, even though the ECM stiffness has a regulatory effect on the directionality of cell migration, normal tissue cells on stiff substrate move less than their diseased counterpart. This observation supports the indication that both oncogene-expressing cells and supra-physiological ECM stiffness are necessary to favor the tumor onset [7, 47]. Seventy-two hours after the irradiation, both normal tissue and metastatic cancer cells on soft substrate reduced significantly the displacement along the principal direction and the migration area, meaning that, even though their directionality increased, as also indicated by TER values, the net displacement along the principal direction decreased together with the velocity. Interestingly, this effect on the migration area was not dependent on the dose administered in the case of healthy cells, whereas it was more relevant for metastatic cells irradiated with the lower dose (Figures 2C,D, Table 1). In this work, we did not explore the mechanism that underlie the behavior of normal tissue and metastatic cancer cells discussed here. Nevertheless, there are some experimental evidences that ionizing radiations could have an important impact on the expression of some proteins, such as integrins, paxillin, FAK, involved in the formation of focal adhesions, that are determinant in both adhesion and migration [48, 49]. Then, changes in pattern involving these proteins are likely to affect both of these processes. In this regard, it has been observed that X-rays can induce over-expression of paxillin [49-51] and promote phosphorylation of FAK and p130cas [49, 52, 53]. The increased expression of paxillin, that is the downstream target of FAK phosphorylation, could be responsible for an increased adhesion of cells after irradiation and consequently for decreased motility, as previously observed in both normal and cancer cells $[50,51,54]$. However, FAK and p130CAS phosphorylation plays a key role in directional migration [55] and the activation of FAK and p130CAS indicated by the increased phosphorylation could explain the increased directionality observed here. Obviously, further research is needed to substantiate these suggestions: the definition of these parameters, that are easy to interpret and do not require high expertise in biophysics (differently from MSD), together with the identification of the molecular mechanisms guiding cell behavior in response to irradiation by means of more complex and tissue-like culture conditions (not only mechanical properties, but also intratumoral solid stresses, dimensionality- $-2 \mathrm{D}$ vs. $3 \mathrm{D}$ vs. $2.5 \mathrm{D}$ curved surfaces, and topographical signals) might generate a basic knowledge with powerful translational significance.

In order to verify the validity of the parameters here introduced, particularly those related to TER, we analyzed the movement of both cells lines in terms of MSD. In fact, in the context of cell migration, the MSD is a good parameter able to carry out information about diffusion coefficient and directionality of a migration trajectory [29, 56]. Our finding suggest that metastatic cancer cells move faster and more persistently compared to normal tissue cells on soft substrate, whereas stiff ECM seems to bolster ballistic motion along rotated $y$-direction of both cell lines, in agreement with experimental evidences previously reported [57-60]. The analysis of MSD components showed that irradiation had important effects on 
the migratory behavior of normal tissue cells, that exhibited more directional migration along $y$-direction when cultured on soft substrate. On the contrary, our findings denote that irradiation did not affect the tendency of metastatic cells to move directionally, as also evidenced by persistence time and TER values (Figure 2) [29], but slowed down in a very forceful way cell velocity, AT values and the displacement along rotated $\mathrm{y}$-direction (Figure 2).

It is particularly relevant to consider that cell motility can be explained by evaluating not only the amount of adhesion in terms of spreading area (for example normal tissue cells become less motile by increasing their adhesion to the substrate), but also in terms of cell shaping: cell cytoskeleton is responsible for cell shape and, consequently, for various types of cell movement [61, 62]. In our previous paper we already analyzed the ability of MCF10A and MDA-MB-231 cells to mechanosense the microenvironment by measuring their spreading area before and after irradiation [29]. In fact, several works demonstrated that when the stiffness and, then, the resistance provided by the substrate increases, cells can generate acto-myosin forces to assemble integrin clusters, a prerequisite to form large and mature focal adhesions which, in turn, regulate spreading area and cytoskeleton assembly [2, 32, 56, 63-65]. In addition to adhesion area, substrate stiffness can affect also other morphological parameters and the intimate connection between cell and microenvironment is often discusses also in terms of cell shaping [66-69]. That being said, a deeper analysis of influence of substrate stiffness and irradiation on cell morphology has been performed by introducing two parameters to describe cell shape: SF and CI (see Materials and Methods section and both ranging from 0 to 1 (Figure 4). SF is related to cell perimeter, assuming max value of 1 for circular cells and approaching 0 when cells have rugged and irregular boundaries. CI quantifies how rounded a cell is and it is equal to 1 for circular cells and approaches to 0 in case of elongated cells. SF helps to emphasize the presence of membrane protrusions (filopodia, lamellipodia, blebs) that are important for adhesion, migration and mechanosensing [70]. MCF10A cells showed a low SF $(\sim 0.2)$, that decreases with substrate stiffness but in a not significant way, whereas their SF resulted to be higher on soft substrate, where cells exhibited a more flattened shape (Figure 5). On the contrary, MDAMB-231 cells exhibited a SF that decreased significantly with substrate stiffness and higher than that of normal tissue cells on soft substrate. Furthermore, normal tissue and metastatic cancer cells displayed similar CI on stiff substrate (Figure 5, Table 2). The effects of irradiation on MCF10A and MDAMB-231 cells were very different and sometimes opposite. In particular, normal tissue cells cultured on both soft and stiff substrates reduced significantly their CI and SF independently on dose received; the only exception was represented by cells on stiff substrate and irradiated with lower dose that increased their SF (Figure 5, Table 2). We suppose that the reduction of $\mathrm{CI}$, indicating a more elongated cell shape, is responsible for the reduction of TER contributing to the increased directionality of MCF10A cells (Figures 2, 3) [71]. In fact, morphological polarization can induce asymmetrical redistribution of forces (lower traction forces at cell rear) and consequently the initiation of a directional migration [72]. Nevertheless, the reduction of SF could be also considered associated to an increased adhesion of normal tissue cells, that consequently exhibit lower migration velocity [29] and reduced AT (Figure 2). On the contrary, the irradiation had not relevant effects on CI and SF of metastatic cells on both soft and stiff substrates. The only exceptions were represented by cells cultured on soft substrate and irradiated with lower dose and cells cultured on stiff substrate and irradiated with higher dose that increased their SF (cells appeared more flattened and to have more regular boundaries). This is in agreement with MSD data, which denote not significant effects of irradiation on the dynamics of migration. On the contrary, the reduced migration of MDA-MB-231 cells can be explained by the enhanced adhesion, higher spreading area and more stretched nuclei [29], all conditions that would suggest a more assembled cell cytoskeleton.

As already discussed, to unravel the mechanisms that regulate cell behavior after irradiation, it will be needed to study the molecular pathways involving adhesion molecules, first of all integrins, FAK and paxillin, which can have important impacts on both adhesion and invasion. In fact, whereas integrin clustering is the fundamental to guarantee a proper adhesion, paxillin has an important role in the regulation of cell adhesion and motility and is a key participant in physiological and pathological context (immune response, epithelial morphogenesis, oxidative stress-which can be consequent to X-ray irradiation, cancer development, and metastasis) and FAK regulates the dynamics of focal adhesion and, consequently, cell migration. It has been already demonstrated that irradiation could promote integrin expression, improve cell adhesion and inhibit invasion capability of glioblastoma cells [48]. Conversely, Rieken et al. observed that increased expression of integrins promoted motile behavior of the same tumor cells [73]. Furthermore, as previously reported, irradiation impacts also on the expression of paxillin and activation of both paxillin and FAK [50, 51, 54, 55] and this could explain the change of mode of migration we observed in our work.

\section{CONCLUSIONS}

In summary, we proposed two additional parameters, TER and AT, to describe cell migration of normal tissue and metastatic cancer cells before and after irradiation when they interact with physiological ( $1.3 \mathrm{kPa})$ and supra-physiological (13 $\mathrm{kPa}$ ) ECM. In particular, we found that irradiation induced a sensitive reduction of TER values in MCF10A cells, indicating that trajectories are more elongated and directionally oriented compared to control condition. On the contrary, TER of MDA-MB-231 cells' trajectories did not change in a relevant way, indicating that the mode of migration of metastatic cancer cells, characterized by directionality and high persistence time [reported in [29]] also in control condition, was not significantly affected by RT. However, irradiation induced also 
a significant decreased of the area explored by cells during their movement (AT). Basing on the results found in terms of morphological parameters and on previous literature here discussed, we supposed that the variations observed in cell motility after irradiation could be ascribed to a different regulation of molecular pathways involving adhesion molecules (integrins, paxillin, FAK), that play a leading role in adhesion and migration. This being said, further investigations will be needed to substantiate these suggestions: the definition of these parameters, that are easy to interpret and do not require high expertise in biophysics (differently from MSD), together with the identification of the molecular mechanisms guiding cell behavior in response to irradiation by means of more complex and tissue-like culture conditions (not only mechanical properties, but also intratumoral solid stresses, dimensionality$-2 \mathrm{D}$ vs. $3 \mathrm{D}$ vs. $2.5 \mathrm{D}$ curved surfaces, and topographical signals) might generate a basic knowledge with powerful translational significance.

\section{REFERENCES}

1. Wells RG. The role of matrix stiffness in regulating cell behavior. Hepatology. (2008) 47:1394-400. doi: 10.1002/hep.22193

2. Fusco S, Panzetta V, Embrione V, Netti PA. Crosstalk between focal adhesions and material mechanical properties governs cell mechanics and functions. Acta Biomater. (2015) 23:63-71. doi: 10.1016/j.actbio.2015.05.008

3. Dufort CC, Paszek MJ, Weaver VM. Balancing forces: architectural control of mechanotransduction. Nat Rev Mol Cell Biol. (2011) 12:30819. doi: $10.1038 / \mathrm{nrm} 3112$

4. Discher DE, Janmey P, Wang Y. Tissue cells feel and respond to the stiffness of their substrate. Science. (2005) 310:1139-43. doi: 10.1126/science.111 6995

5. Guimarães CF, Gasperini L, Marques AP, Reis RL. The stiffness of living tissues and its implications for tissue engineering. Nat Rev Mater. (2020) 5:351-70. doi: 10.1038/s41578-019-0169-1

6. Panzetta V, Musella I, Rapa I, Volante M, Netti PA, Fusco S. Mechanical phenotyping of cells and extracellular matrix as grade and stage markers of lung tumor tissues. Acta Biomater. (2017) 57:334-41. doi: 10.1016/j.actbio.2017.05.002

7. Panciera T, Citron A, Di Biagio D, Battilana G, Gandin A, Giutti S, et al. Reprogramming normal cells into tumour precursors requires ECM stiffness and oncogene-mediated changes of cell mechanical properties. Nat Mater. (2020) 19:797-806. doi: 10.1038/s41563-020-0615-x

8. Panciera T, Azzolin L, Cordenonsi M, Piccolo S. Mechanobiology of YAP and TAZ in physiology and disease. Nat Rev Mol Cell Biol. (2017) 18:75870. doi: 10.1038/nrm.2017.87

9. Walker C, Mojares E, del Río Hernández A. Role of extracellular matrix in development and cancer progression. Int J Mol Sci. (2018) 19:3028. doi: 10.3390/ijms19103028

10. He X, Lee B, Jiang Y. Cell-ECM interactions in tumor invasion. In: Rejniak K. editor. Systems Biology of Tumor Microenvironment. Cham: Springer (2016). p. $73-91$.

11. Mohan V, Das A, Sagi I. Emerging roles of ECM remodeling processes in cancer. Semin Cancer Biol. (2020) 62:192200. doi: 10.1016/j.semcancer.2019.09.004

12. Aguilar-Cuenca R, Juanes-García A, Vicente-Manzanares $M$. Myosin II in mechanotransduction: master and commander of cell migration, morphogenesis, and cancer. Cell Mol Life Sci. (2014) 71:479-92. doi: 10.1007/s00018-013-1439-5

13. Hood JD, Cheresh DA. Role of integrins in cell invasion and migration. Nat Rev Cancer. (2002) 2:91-100. doi: 10.1038/ $\operatorname{nrc727}$

\section{DATA AVAILABILITY STATEMENT}

The raw data supporting the conclusions of this article will be made available by the authors, without undue reservation.

\section{AUTHOR CONTRIBUTIONS}

VP and SF conceived of the presented work and wrote the original draft. VP and GL carried out the experiments. VP performed data analysis. CA defined and performed radiation treatment plans. All authors discussed the results and contributed to the final version of the manuscript. All authors contributed to the article and approved the submitted version.

\section{FUNDING}

This work was supported by Modeling and Verification for Ion beam Treatment planning (MoVe-IT) project, INFN CSN5 Call.

14. Müller T, Bain G, Wang X, Papkoff J. Regulation of epithelial cell migration and tumor formation by $\beta$-catenin signaling. Exp Cell Res. (2002) 280:11933. doi: 10.1006/excr.2002.5630

15. Dongre A, Weinberg RA. New insights into the mechanisms of epithelialmesenchymal transition and implications for cancer. Nat Rev Mol Cell Biol. (2019) 20:69-84. doi: 10.1038/s41580-018-0080-4

16. Deryugina EI, Quigley JP. Matrix metalloproteinases and tumor metastasis. Cancer Metastasis Rev. (2006) 25:9-34. doi: 10.1007/s10555-006-7886-9

17. Warren JSA, Xiao Y, Lamar JM. YAP/TAZ activation as a target for treating metastatic cancer. Cancers. (2018) 10:115. doi: 10.3390/cancers10040115

18. Hsiang-his HH, Kuo CC, Lin BX, Huang YH, Lin CW. Elevation of YAP promotes the epithelial-mesenchymal transition and tumor aggressiveness in colorectal cancer. Exp Cell Res. (2017) 350:218-25. doi: 10.1016/j.yexcr.2016.11.024

19. Cheng GZ, Chan J, Wang Q, Zhang Q, Sun CD, W LH. Twist transcriptionally up-regulates AKT2 in breast cancer cells leading to increased migration, invasion, and resistance to paclitaxel. Cancer Res. (2007) 67:197987. doi: 10.1158/0008-5472.CAN-06-1479

20. Yang Z, Zhang X, Gang H, Li X, Li Z, Wang T, et al. Up-regulation of gastric cancer cell invasion by Twist is accompanied by $\mathrm{N}$-cadherin and fibronectin expression. Biochem Biophys. Res. Commun. (2007) 358:92530. doi: 10.1016/j.bbrc.2007.05.023

21. Weichselbaum RR, Dahlberg W, Beckett M, Karrison T, Miller D, Clark J. et al. Radiation-resistant and repair-proficient human tumor cells may be associated with radiotherapy failure in head- and neck-cancer patients. Proc Natl Acad Sci. (1986) 83:2684-2688. doi: 10.1073/pnas.83.8.2684

22. Schaapveld M, Aleman BMP, van Eggermond AM, Janus CPM, Krol ADG, van der Maazen RWM, et al. Second cancer risk up to 40 years after treatment for Hodgkin's lymphoma. N Engl J Med. (2015) 373:2499511. doi: 10.1056/NEJMoa1505949

23. Grantzau T, Overgaard J. Risk of second non-breast cancer after radiotherapy for breast cancer: a systematic review and meta-analysis of 762,468 patients. Radiother Oncol. (2015) 114:56-65. doi: 10.1016/j.radonc.2014.10.004

24. Journy NM, Morton LM, Kleinerman RA, Bekelman JE, Berrington de Gonzalez A. Second primary cancers after intensity-modulated vs 3dimensional conformal radiation therapy for prostate cancer. JAMA Oncol. (2016) 2:1368-70. doi: 10.1001/jamaoncol.2016.1368

25. Vilalta M, Rafat M, Graves EE. Effects of radiation on metastasis and tumor cell migration. Cell Mol Life Sci. (2016) 73:29993007. doi: 10.1007/s00018-016-2210-5

26. Imaizumi H, Nishihara A, Minami K, Koisumi M, Matsuura N, Hieda M. Xray-enhanced cancer cell migration requires the linker of nucleoskeleton and cytoskeleton complex. Cancer Sci. (2018) 109:1158-65. doi: 10.1111/cas.13545 
27. Jung JW, Hwang SY, Hwang JS, Oh ES, Park S, Han IO Ionising radiation induces changes associated with epithelial-mesenchymal transdifferentiation increased cell motility of A549 lung epithelial cells. Eur J Cancer. (2007) 43:1214-24. doi: 10.1016/j.ejca.2007.01.034

28. De Bacco F, Luraghi P, Medico E, Reato G, Girolami F, Perera T, et al. Induction of MET by ionizing radiation and its role in radioresistance and invasive growth of cancer. J Natl Cancer Inst. (2011) 103:64561. doi: 10.1093/jnci/djr093

29. Panzetta V, La Verde G, Pugliese M, Artiola V, Arricchiello C, Muto P, et al. Adhesion and migration response to radiation therapy of mammary epithelial and adenocarcinoma cells interacting with different stiffness substrates. Cancers. (2020) 12:1170. doi: 10.3390/cancers 12051170

30. Hohmann T, Grabiec U, Vogel C, Ghabdan C, Ensminger S, Bache $\mathrm{M}$, et al. The impact of non-lethal single-dose radiation on tumor invasion and cytoskeletal properties. Int J Mol Sci. (2017) 18:2001. doi: 10.3390/ijms18092001

31. Siva S, MacManus MP, Martin RF, Martina OA. Abscopal effects of radiation therapy: a clinical review for the radiobiologist. Cancer Lett. (2015) 35:8290. doi: 10.1016/j.canlet.2013.09.018

32. Panzetta V, Guarnieri D, Paciello A, Della Sala F, Muscetti O, Raiola L, et al. ECM mechano-sensing regulates cytoskeleton assembly and receptormediated endocytosis of nanoparticles. ACS Biomater Sci Eng. (2017) 3:158694. doi: 10.1021/acsbiomaterials.7b00018

33. DeSantis CE, Ma J, Gaudet MM, Newman LA, Miller KDM, Goding Sauer A, et al. Breast cancer statistics, 2019. CA Cancer J Clin. (2019) 69:43851. doi: $10.3322 /$ caac. 21583

34. Siegel RL, Miller KD, Jemal A. Cancer statistics, 2019. CA Cancer J Clin. (2019) 69:7-34. doi: 10.3322/caac.21551

35. Redig AJ, McAllister SS. Breast cancer as a systemic disease: a view of metastasis. J Intern Med. (2013) 274:113-26. doi: 10.1111/joim.12084

36. Lawson DA, Bhakta N, Kessenbrock K, Prummel KD, Yu Y, Takai K et al. Single-cell analysis reveals a stem-cell program in human metastatic breast cancer cells. Nature. (2015) 526:131-5. doi: 10.1038/nature15260

37. Fusco S, Panzetta V, Netti PA. Mechanosensing of substrate stiffness regulates focal adhesions dynamics in cell. Meccanica. (2017) 52:338998. doi: 10.1007/s11012-017-0676-3

38. Carragher NO, Frame MC. Focal adhesion and actin dynamics: a place where kinases and proteases meet to promote invasion. Trends Cell Biol. (2004) 14:241-9. doi: 10.1016/j.tcb.2004.03.011

39. Schlaepfer DD, Mitra SK. Multiple connections link FAK to cell motility and invasion. Curr Opin Genet Dev. (2004) 14:92-101. doi: 10.1016/j.gde.2003.12.002

40. Luo M, Guan JL. Focal adhesion kinase: a prominent determinant in breast cancer initiation, progression and metastasis. Cancer Lett. (2010) 289:12739. doi: 10.1016/i.canlet.2009.07.005

41. Wu GS, Aong YL, Yin ZQ, Guo JJ, Wang SP, Zhao WW, et al. Ganoderiol A-enriched extract suppresses migration and adhesion of MDA-MB-231 cells by inhibiting FAK-SRC-paxillin cascade pathway. PLoS ONE. (2013) 8:e76620. doi: 10.1371/journal.pone.0076620

42. McLean GW Avizienyte E, Frame MC. Focal adhesion kinase as a potential target in oncology. Expert Opin Pharmacother. (2003) 4:22734. doi: 10.1517/14656566.4.2.227

43. Peng Y, Chen Z, Chen Y, Li S, Jiang Y, Yang H. ROCK isoforms differentially modulate cancer cell motility by mechanosensing the substrate stiffness. Acta Biomater. (2019) 88:86-101. doi: 10.1016/j.actbio.2019.02.015

44. Kamai T, Tsujii T, Arai K, Takagi K, Asami H, Ito Y, et al. Significant association of Rho/ROCK pathway with invasion and metastasis of bladder cancer. Clin Cancer Res. (2003) 9:2632-41. Available online at: https://clincancerres. aacrjournals.org/content/9/7/2632

45. Wong CC, Wong CM, Tung EK, Man K, Ng IO. Rho-kinase 2 is frequently overexpressed in hepatocellular carcinoma and involved in tumor invasion. Hepatology. (2009) 49:1583-94. doi: 10.1002/hep.22836

46. Lane J, Martin TA, Watkins G, Mansel RE, Jiang WG. The expression and prognostic value of ROCK I and ROCK II and their role in human breast cancer. Int J Oncol. (2008) 33:585-93. doi: 10.3892/ijo_00000044

47. Seewaldt V. ECM stiffness paves the way for tumor cells. Nat Med. (2014) 20:332-3. doi: 10.1038/nm.3523
48. Cordes N, Hansmeier B, Beinke C, Meineke D, Van Beuningen D. Irradiation differentially affects substratum-dependent survival, adhesion, and invasion of glioblastoma cell lines. Br J Cancer. (2003) 89:212232. doi: $10.1038 /$ sj.bjc.6601429

49. Beinke C, Van Beuningen D, Cordes N. Ionizing radiation modules of the expression and tyrosine phosphorylation of the focal adhesionassociated proteins focal adhesion kinase (FAK) and its substrates p130cas and paxillin in A549 human lung carcinoma cells in vitro. Int J Radiat Biol. (2003) 79:721-31. doi: 10.1080/09553000310001 610231

50. Panzetta V, De Menna M, Bucci D, Giovannini V, Quarto $\mathrm{M}$, Fusco $\mathrm{S}$, et al. X-ray irradiation affects morphology, proliferation and migration rate of healthy and cancer cells. $J$ Mech Med Biol. (2015) 15:1540022. doi: 10.1142/S0219519415 400229

51. Panzetta V, Musella I, Pugliese M, Piccolo C, Pasqua G, Netti PA, et al. Effects of high energy X-rays on cell morphology and functions 2017. In: IEEE 5th Portuguese Meeting on Bioengineering (ENBENG). Coimbra: IEEE (2017).

52. Wick W, Wick A, Schulz JB, Dichgans J, Rodemann HP, Weller M. Prevention of irradiation-induced glioma cell invasion by temozolomide involves caspase 3 activity and cleavage of focal adhesion kinase. Cancer Res. (2002) 62:1915-9. Available online at: https://cancerres.aacrjournals.org/content/62/ 6/1915.long

53. Eke I, Cordes N. Radiobiology goes 3D: how ECM and cell morphology impact on cell survival after irradiation. Radiother Oncol. (2011) 99:2718. doi: 10.1016/j.radonc.2011.06.007

54. Salgia R, Li JL, Ewaniuk DS, Wang YB, Sattler M, Chen WC, et al. Expression of the focal adhesion protein paxillin in lung cancer and its relation to cell motility. Oncogene. (1999) 18:67-77. doi: 10.1038/sj.onc.1202273

55. Yu JA, Deakin NO, Turner CE. Paxillin-kinase-linker tyrosine phosphorylation regulates directional cell migration. Mol Biol Cell. (2009) 20:4706-19. doi: 10.1091/mbc.e09-07-0548

56. Gorelik R, Gautreau A. Quantitative and unbiased analysis of directional persistence in cell migration. Nat Protoc. (2014) 9:1931. doi: 10.1038/nprot.2014.131

57. Stroka KM, Aranda-Espinoza H. Neutrophils display biphasic relationship between migration and substrate stiffness. Cell Motil Cytoskeleton. (2009) 66:328-41. doi: $10.1002 / \mathrm{cm} .20363$

58. Schlüter DK, Ramis-Conde I, Chaplain MAJ. Computational modeling of single-cell migration: the leading role of extracellular matrix fibers. Biophys J. (2012) 103:1141-51. doi: 10.1016/j.bpj.2012.07.048

59. Levental KR, Yu H, Kass L, Lakins JN, Egeblad M, et al. Matrix crosslinking forces tumor progression by enhancing integrin signaling. Cell. (2009) 139:891-906. doi: 10.1016/j.cell.2009.10.027

60. Acerbi I Cassereau L, Dean I, Shi Q, Au A, Park C, et al. Human breast cancer invasion and aggression correlates with ECM stiffening and immune cell infiltration. Integr Biol. (2015) 7:1120-34. doi: 10.1039/c5ib00040h

61. Pollard TD Cooper JA. Actin, a central player in cell shape and movement. Science. (2009) 326:1208-12. doi: 10.1126/science.1175862

62. Mogilner A, Keren K. The shape of motile cells. Curr Biol. (2009) 19:R76271. doi: $10.1016 /$ j.cub.2009.06.053

63. Engler A, Bacakova L, Newman C, Hategan A, Griffin M, Discher D. Substrate compliance versus ligand density in cell on gel responses. Biophys J. (2004) 86:617-28. doi: 10.1016/S0006-3495(04)74140-5

64. Reinhart-King CA, Dembo $M$, Hammer DA. The dynamics and mechanics of endothelial cell spreading. Biophys J. (2005) 89:676-89. doi: 10.1529/biophysj.104.054320

65. Califano JP, Reinhart-King CA. A balance of substrate mechanics and matrix chemistry regulates endothelial cell network assembly. Cell Mol Bioeng. (2008) 1:122. doi: $10.1007 / \mathrm{s} 12195-008-0022-\mathrm{x}$

66. Califano JP, Reinhart-King CA. Substrate stiffness and cell area predict cellular traction stresses in single cells and cells in contact. Cell Mol Bioeng. (2010) 3:68-75. doi: 10.1007/s12195-010-0102-6

67. Yeung T, Georges PC, Flanagan LA, Marg B, Ortiz M, Funaki M, et al. Effects of substrate stiffness on cell morphology, cytoskeletal structure, and adhesion. Cell Motil. Cytoskeleton. (2005) 60:24-34. doi: 10.1002/cm. 20041 
68. Chiang MY, Yangben Y, Lin NJ, Zhong JL, Yang L. Relationships among cell morphology, intrinsic cell stiffness and cell-substrate interactions. Biomaterials. (2013) 34:9754-62. doi: 10.1016/j.biomaterials.2013. 09.014

69. Panzetta V, Fusco S, Netti PA. Cell mechanosensing is regulated by substrate strain energy rather than stiffness. Proc Natl Acad Sci USA. (2019) 116:2200413. doi: $10.1073 /$ pnas. 1904660116

70. Krause M, Gautreau A. Steering cell migration: Lamellipodium dynamics and the regulation of directional persistence. Nat Rev Mol Cell Biol. (2014) 15:577-90. doi: 10.1038/nrm3861

71. Petrie RJ, Doyle AD, Yamada KM. Random versus directionally persistent cell migration. Nat Rev Mol Cell Biol. (2009) 10:538-49. doi: 10.1038/nrm2729

72. Hennig K, Wang I, Moreau P, Valon L, DeBeco S, Coppey M, et al. Stickslip dynamics of cell adhesion triggers spontaneous symmetry breaking and directional migration of mesenchymal cells on one-dimensional lines. Sci Adv. (2020) 6:eaau5670. doi: 10.1126/sciadv.aau5670
73. Rieken S, Habermehl D, Wuerth L, Brons S, Mohr A, Lindel K, et al. Carbon ion irradiation inhibits glioma cell migration through downregulation of integrin expression. Int $J$ Radiat. (2012) 83:3949. doi: 10.1016/j.ijrobp.2011.06.2004

Conflict of Interest: The authors declare that the research was conducted in the absence of any commercial or financial relationships that could be construed as a potential conflict of interest.

Copyright $\odot 2020$ Panzetta, La Verde, Pugliese, Arrichiello, Muto, La Commara, D'Avino, Netti and Fusco. This is an open-access article distributed under the terms of the Creative Commons Attribution License (CC BY). The use, distribution or reproduction in other forums is permitted, provided the original author(s) and the copyright owner(s) are credited and that the original publication in this journal is cited, in accordance with accepted academic practice. No use, distribution or reproduction is permitted which does not comply with these terms. 